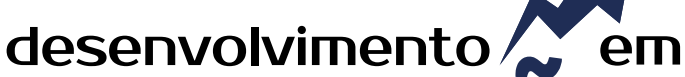 QUESTAOO
}

\section{INOVAÇÃO NO DESENVOLVIMENTO RURAL E REGIONAL: O Caso das Novidades Multidimensionais das Agroindústrias Familiares}

http://dx.doi.org/10.21527/2237-6453.2021.56.11734

Recebido em: 19/11/2020

Aceito em: 5/5/2021

\author{
Marcio Gazolla, ${ }_{1}^{1}$ Mariana Beal Dengo, ${ }^{2}$ Miguel Angelo Perondi²
}

\begin{abstract}
RESUMO
A pesquisa buscou identificar e analisar as motivações e os diferentes tipos de novidades nos sistemas produtivos e nas agroindústrias familiares e seus efeitos nas famílias e nos processos de desenvolvimento rural e regional. A metodologia foi desenvolvida com base em dados qualitativos e quantitativos, principalmente entrevistando agricultores (quatro), técnicos e agentes de desenvolvimento rural (oito), no município de Verê/PR, em 2018. As abordagens teóricas utilizadas foram a Perspectiva Orientada ao Ator (POA), de Norman Long, e a Perspectiva Multinível e Coevolucionária (PMN), de autores que trabalham com abordagens sociotécnicas. Esta pesquisa encontrou diferentes tipos de novidades, tais como: produtiva, tecnológica, organizacional, de construção de mercados e de sustentabilidade ambiental. Tais novidades garantiram uma melhor condição de vida e trabalho para as famílias estudadas e contribuíram para explicar sua permanência nas áreas rurais. Com essas novidades, os agricultores alcançaram um sistema de produção mais sustentável, com maior autonomia produtiva, comercial e financeira e, ao mesmo tempo, passaram a produzir alimentos mais saudáveis. Também foi observado, no entanto, que existem desafios à sedimentação de novidades, como: a incerteza na sucessão familiar, a continuidade da rede social dos atores e a dependência de políticas e ações públicas do Estado.
\end{abstract}

Palavras-chave: novidades; alimentação; agroindústrias familiares; desenvolvimento regional e rural.

INNOVATION IN DEVELOPMENT RURAL AND REGIONAL: THE CASE OF MULTIDIMENSIONS NOVELTIES IN THE FAMILY AGROINDUSTRIES

\begin{abstract}
The research sought to identify and analyze the motivations and the different types of novelties in the productive systems and in the family agroindustries and their effects on families and on the processes of rural and regional development. The methodology was developed based on qualitative and quantitative data, mainly interviewing farmers (four), technicians and rural development agents (eight), in the municipality of Verê/PR, in 2018. The theoretical approaches used were the Actor Oriented Perspective (POA) of the Norman Long and the Multilevel and Co-Evolutionary Perspective (PMN) of authors working with socio-technical approaches. This research found different types of novelties, such as: productive, technological, organizational, market building and environmental sustainability. Such novelties ensured a better living and working condition for the families studied and corroborated to explain their permanence in rural areas. With these novelties, farmers achieved a more sustainable production system, with greater productive, commercial and financial autonomy, and at the same time, started to produce healthier food. However, it was also observed that there are challenges to the sedimentation of novelties, such as: the uncertainty in family succession, the continuity of the social network of the actors and the dependence on public policies and actions of the State.
\end{abstract}

Keywords: novelties; foods; family agroindustries; regional and rural development.

\footnotetext{
${ }^{1}$ Autor correspondente. Universidade Tecnológica Federal do Paraná (UTFPR). Rua Via do Conhecimento - Fraron. Pato Branco/PR, Brasil. CEP 85503-390. http://lattes.cnpq.br/0922348490725786. https://orcid.org/0000-0002-4807-6683. marciogazolla1@gmail.com

2 Universidade Tecnológica Federal do Paraná (UTFPR). Pato Branco/PR, Brasil.
} 


\section{INTRODUÇÃO}

Com o processo de modernização da agricultura e o crescimento da população urbanizada depois dos anos 70 no Brasil, a produção de alimentos gradualmente voltou-se à larga escala, com produtos gerados em massa, uniformes e também especializada em algumas culturas e criações, espacialmente grãos, carnes e algumas frutas. Neste mesmo período, as grandes indústrias alimentícias desenvolveram-se com rapidez, deixando as pequenas agroindústrias na marginalidade (BAGGIO, 2010). Ploeg (2008) denominou este movimento de formação de grandes corporações internacionais de alimentos como impérios alimentares.

Já em relação às inovações usadas na agricultura, que passou a ser considerada "moderna" pelos seus idealizadores (governo, agências de pesquisa, empresas de insumos, entre outros), passaram a ser produzidas por meio de pesquisas científicas, fabricadas nos mercados e comercializadas para os agricultores, geralmente com o intuito de reduzir o tempo de produção e aumentar a produtividade. Os agricultores como meros usuários das tecnologias, foram gradativamente perdendo sua autonomia, ao comprar os insumos e adotar práticas agrícolas externas a sua realidade social e aos seus conhecimentos, pagando altos preços pelas inovações que provinham dos mercados (WISKERKE; PLOEG, 2004).

Em meio a esse processo, parte da agricultura familiar tornou-se responsável pela diversidade de alimentos frescos e elaborados artesanalmente, com características específicas que estão ligadas ao local de produção, com práticas e conhecimentos usados com base na história dos agricultores. Esta parcela da agricultura familiar encontra-se fundamentada numa produção de alimentos sustentável, com redução da emissão de gases de efeito estufa, uma vez que a maior parte da comercialização é feita por cadeias curtas, sem transportar por longas distâncias (GAZOLLA; SCHNEIDER, 2017). Por exemplo, este é o caso da produção de matérias-primas que são transformadas em alimentos e produtos elaborados com maior valor agregado, por agroindústrias familiares (AGFs) no Sul do país.

Para Mior (2005), a agroindústria familiar rural é concebida como uma forma de organização na qual a família tem o papel central na produção, pois produz, processa e/ou transforma parte de sua produção agrícola e/ou pecuária, visando a obter maior valor de troca que ocorre na comercialização. Enquanto o processamento e a transformação de alimentos ocorrem geralmente na cozinha das agricultoras, a agroindústria constitui-se num novo espaço e num novo empreendimento social e econômico. Algumas agroindústrias possuem práticas sociotécnicas que são consideradas inovadoras e criativas, as quais pretende-se investigar neste trabalho (MOORS; RIP; WISKERKE, 2004).

As novidades são uma forma de inovação alinhada aos anseios dos seus usuários, uma vez que são desenvolvidas por quem as utiliza. Como Ploeg et al. (2004) conceituaram, uma novidade pode ser a modificação das práticas usuais ou a criação de uma nova prática; uma nova maneira de fazer e pensar que carrega potencial para ser superior às rotinas existentes. As novidades são definidas como multidimensionais, pois baseiam-se nos conhecimentos locais, nos recursos do território, nas redes sociais dos agricultores e nas práticas sociotécnicas do repertório sociocultural dos atores envolvidos em torno das iniciativas. Além disso, os agricultores desenvolvem suas novidades em diferentes direções, desde o sistema de produção, comercialização, processos tecnológicos, sustentabilidade ambiental, organização social, observando-se que em razão disso é possível denominá-las de multifacetadas (WISKERKE; PLOEG, 2004). 
Nesse sentido, a pesquisa buscou identificar e analisar as motivações e os diferentes tipos de novidades nos sistemas produtivos e nas agroindústrias familiares e seus efeitos nas famílias e nos processos de desenvolvimento rural e regional. Para atingir este objetivo, metodologicamente, aplicou-se 12 entrevistas semiestruturadas com questões qualitativas e quantitativas, com 4 agroindústrias e 8 agentes de desenvolvimento, além de usar dados secundários. A pesquisa foi desenvolvida no município de Verê/PR, no ano de 2018. As questões que lastrearam a realização da pesquisa foram de duas naturezas: (a) Quais são as novidades geradas nos sistemas de produção, nas agroindústrias familiares e suas características?; (b) Quais transições sociotécnicas ocorrem nos processos de desenvolvimento regional e rural a partir das novidades construídas pelas agroindústrias familiares?

O presente artigo está organizado em três seções, além da introdução e das considerações finais. A primeira seção contém a metodologia utilizada que deu suporte à pesquisa. $\mathrm{Na}$ segunda está a abordagem teórica utilizada. A terceira seção apresenta e analisa os resultados obtidos na investigação.

\section{METODOLOGIA DE INVESTIGAÇÃO: O Caminho Percorrido e os Instrumentos de Levantamento de Dados e Informações}

A pesquisa utilizou-se de dados quantitativos (primários) e secundários advindos do Instituto Brasileiro de Geografia e Estatística (IBGE), Instituto Paranaense de Desenvolvimento Econômico e Social (Ipardes) e da Secretaria Municipal de Agricultura de Verê. Também foram aplicadas 12 entrevistas semiestruturadas que geraram dados qualitativos e quantitativos para possibilitar o entendimento das novidades geradas, suas características e efeitos sobre os processos de desenvolvimento rural e regional.

O número de agroindústrias que entraria na investigação foi definido de forma intencional e dirigida para selecionar agroindústrias que possuíssem novidades a serem analisadas. 0 primeiro passo foi realizar uma pesquisa exploratória, no início de 2018 , em que se visitou em torno de 10 agroindústrias, em conversa informal, visando a selecionar apenas as que apresentassem novidades em seus processos sociotécnicos. Das 10 AGFs visitadas informalmente, 4 foram escolhidas por possuírem, em suas dinâmicas, processos sociais que geravam novidades. As AGFs selecionadas foram codificadas de $\mathrm{C} 1$ a $\mathrm{C} 4$ (C: casos). Além das agroindústrias, também foram entrevistados 8 técnicos e agentes de desenvolvimento, pertencentes a diferentes organizações e instituições que apoiam as agroindústrias em plano local e regional. Os técnicos entrevistados foram codificados de T1 a T8 (T: técnicos).

Nas entrevistas foram captados dados quantitativos e qualitativos. As entrevistas foram gravadas, transcritas e aplicada análise de conteúdo nas informações qualitativas. A análise de conteúdo realizou-se lendo e relando os depoimentos, buscando o entendimento da dinâmica da variável em investigação (novidades) e dos indicadores que foram mobilizados para compreendê-las em cada parte da pesquisa (por exemplo, origem das novidades, motivações dos agricultores, a renda gerada, etc.). Os trechos mais importantes das falas dos atores foram utilizados no trabalho, como evidência qualitativa do processo social que se estava analisando (MUTTI, 2003; MINAYO, 1999). 
Algumas características das quatro unidades familiares e agroindústrias investigadas estão expostas no Quadro 1. A origem da agroindústria C1 foi motivada pelos seus fundadores em razão da alta declividade do terreno, que impedia a mecanização agrícola. Já as outras três surgiram a partir de 2003 e são resultado da intervenção de políticas municipais de incentivo às agroindústrias. São produzidos por estes quatro casos nove tipos de alimentos in natura e fabricados, todos de origem vegetal. As unidades de produção possuem, em média, 15,62 hectares, mas boa parte dessa área serve para desenvolvimento de outras atividades agrícolas, moradia e/ou de reservas florestais. A área média utilizada para produção de matérias-primas que são depois processadas nas agroindústrias é em torno de 3,30 hectares.

Quadro 1 - Características das unidades de produção e das agroindústrias investigadas

\begin{tabular}{|c|c|c|c|c|}
\hline AGFs & $\begin{array}{c}\text { Ano de } \\
\text { criação }\end{array}$ & $\begin{array}{c}\text { Alimentos e produtos (in natura e } \\
\text { fabricados) }\end{array}$ & Área Total (ha) & $\begin{array}{c}\text { Área para uso das } \\
\text { agroindústrias (ha) }\end{array}$ \\
\hline C1 & 1993 & Uva, vinhos, graspa, suco de uva e doces & 38,5 & 4,0 \\
\hline C2 & 2003 & Doces e conservas & 9,6 & 1,0 \\
\hline C3 & 2006 & Uva e suco de uva & 7,4 & 2,42 \\
\hline C4 & 2015 & Açúcar mascavo e queijos & 7,0 & 5,79 \\
\hline Total & - & - & $\mathbf{6 2 , 5}$ & $\mathbf{1 3 , 2 1}$ \\
\hline Média & & & $\mathbf{1 5 , 6 2}$ & $\mathbf{3 , 3 0}$ \\
\hline
\end{tabular}

Fonte: Pesquisa de campo (2018).

O município escolhido para a investigação foi Verê/PR, que está localizado na Região Sudoeste do Estado. O município possui área territorial de $311.801 \mathrm{~km}^{2}$, população de 7.878 habitantes, IDH de 0,7 , ocupando 127 a posição no ranking estadual (IBGE, 2016). A seleção deste local para o desenvolvimento da investigação deve-se fundamentalmente a três conjuntos de fatores: a) Devido ao processo histórico e instigante de produção agroindustrial de alimentos, que abastecem os mercados locais e programas governamentais; b) A existência de atividades de turismo (rural e outros tipos), devido à existência de águas termais no município (balneário, hotel, rotas, etc.), que potencializam a produção de novidades nas agroindústrias; c) A presença de organizações sociais que trabalham no apoio e no desenvolvimento das AGFs, por exemplo, e só para citar uma das principais, o Centro de Apoio e Promoção da Agroecologia (Capa), que potencializam a produção e transformação de alimentos ecológicos. ${ }^{3}$

No caso da presente investigação, as novidades descobertas são concebidas como tais quando são comparadas ao regime sociotécnico alimentar hegemônico, que possui as seguintes características centrais, embora possa haver outras: oligopolização dos mercados de alimentos por grandes empresas; produção padronizada e química/industrial dos produtos; cadeias longas de produção-distribuição-consumo dos produtos; valor agregado fica com os impérios alimentares, que geralmente exploram agricultores e consumidores; as práticas ambientais são controversas e insustentáveis; não preocupação com desigualdades sociais e vulnerabilidades dos atores sociais que trabalham no setor de alimentares além de grandes desperdícios de alimentos em todas as suas etapas da cadeia de distribuição (food waste) (GAZOLLA, 2020).

\footnotetext{
${ }^{3}$ A Figura 2 colocada na seção dos resultados de pesquisa do texto traduz a rede social inovativa de instituições e demais organizações sociais que atuam neste local, em prol do desenvolvimento das agroindústrias.
} 


\section{PERSPECTIVA ORIENTADA AOS ATORES (POA) E MULTINÍVEL E CO-EVOLUCIONÁRIA (PMN): Aportes Teóricos Para o Estudo das Novidades}

Para o estudo das novidades nas agroindústrias, um dos enfoques teóricos mobilizados foi a Perspectiva Orientada ao Ator (POA). Segundo Long (2006), os atores sociais são todas as pessoas, entidades sociais e outros agrupamentos que são capazes de conhecer, avaliar situações-problema e organizar respostas adequadas a estas. Dessa forma, os agricultores são considerados atores sociais nesta investigação, pois são capazes de dar respostas para uma dada situação problemática por meio dos seus conhecimentos e do repertório cultural que possuem. Os atores são todos aqueles que possuem agência (podendo ser pessoas físicas, governo, redes, etc.). A POA caracteriza os atores sociais como protagonistas de seus projetos de vida, estratégias e condutores dos seus processos de desenvolvimento rural e regional.

A noção de agência é o que permite aos agricultores gerenciar seus projetos com respostas diferenciadas às estratégias e circunstâncias geradas por atores externos e não como simples imposições. Por meio do conceito de agência, ressalta-se a abordagem que coloca os atores sociais no centro das atenções e os retira da passividade. Além disso, consegue-se analisar seus repertórios culturais, processos de mediação, interfaces de relacionamentos com outros atores, interações sociais e compreender os seus projetos de desenvolvimento e "mundos" de vida (LONG, 2006).

No caso da análise das novidades nas unidades de produção e agroindústrias, utiliza-se o conceito de agência dos agricultores para compreender como eles constroem novidades em inter-relações com outros atores e agentes de desenvolvimento. A POA também é importante em termos de analisar os tipos de conhecimentos que os atores sociais manejam para construir as novidades, posto que estas baseiam-se em conhecimentos hibridizados (tácitos, contextuais, populares, científicos, educação formal, etc.) (LONG; PLOEG, 2015).

Para compreender o processo de produção de novidades que ocorreu nos sistemas de produção familiares e nas agroindústrias estudadas fez-se necessário também a utilização da Perspectiva Multinível e Coevolucionária (PMN), que tem origem na Sociologia da Tecnologia e na Economia Evolucionária. Esta abordagem é utilizada para avaliar as transformações sociotécnicas nos processos de desenvolvimento regional e rural, produzidas pelos agricultores por intermédio da agência que possuem e utilizando-se de recursos do local, conhecimentos, redes sociais e elementos sociotécnicos disponíveis (GEELS; SCHOT, 2002).

A PMN divide os níveis analíticos ilustrados na Figura 1, heuristicamente, em três: os nichos, o regime e a paisagem sociotécnica e, por esta razão, é denominada de multinível. Além disso, a PMN também abarca a noção de (co)evolução, uma vez que os processos sociotécnicos (co)evoluem no tempo e espaços sociais em que os atores estão situados historicamente (GEELS; SCHOT, 2002; MOORS; RIP; WISKERKE, 2004) (Figura 1). É importante ressaltar que os três níveis heurísticos estão institucionalmente interligados, possuindo frequente comunicação entre si, dependendo das dinâmicas sociotécnicas que ocorrem. 
Figura 1 - Perspectiva Multinível e Coevolucionária (PMN) e as novidades

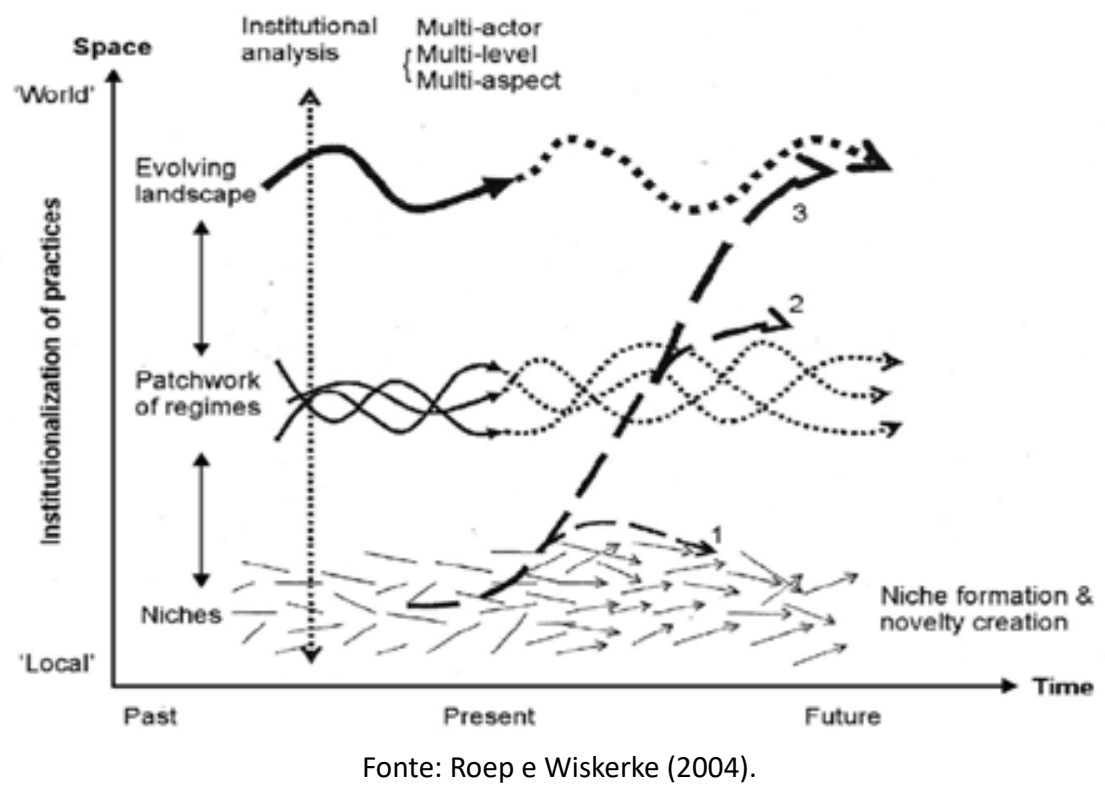

A paisagem sociotécnica é o nível macro de estruturação dos processos das sociedades, podendo ser caracterizada como as relações Norte-Sul, as mudanças climáticas, a divisão entre países ricos e em desenvolvimento, entre outros aspectos, que se encontram sedimentados e são de difícil mudança. $O$ elemento conceitual chave da noção de paisagem sociotécnica é sua imutabilidade através do tempo e nos espaços sociotécnicos (GAZOLLA, 2020).

Já a noção de regime sociotécnico é definida como a gramática de regras e normas que governam os processos de produção de inovações. Assim compreendido, refere-se ao conjunto de institucionalidades que estão presentes em cada sociedade e local, realizando a governança dos processos de construção de inovações e também de regulação dos nichos sociotécnicos, que são os locais em que as novidades emergem. No caso das tecnologias, o regime sociotécnico está colocado entre o nível das paisagens e dos nichos, sendo definido como nível meso de estruturação ou de análise dos processos tecnológicos e inovativos (GEELS; SCHOT, 2002).

Segundo Roep e Wiskerke (2004), os nichos sociotécnicos são o nível micro de estruturação e análise, caracterizados como os locais em que ocorre a geração das novidades, por meio dos processos de incubação das mesmas, mas também mediante as práticas proativas e criativas dos atores sociais como se salientou anteriormente, a partir das ideias de Norman Long. Nos nichos as novidades têm sua dinâmica determinada, podendo serem radicais (criarem novam regras e romperem com as normas do regime sociotécnico), sendo este processo chamado de transição sociotécnica, quando a partir do surgimento de uma novidade ocorrem mudanças multidimensionais em outros aspectos, sejam eles sociais, organizacionais, conhecimentos, econômicos, ambientais, tecnológicos ou em outras dimensões, algumas até incomensuráveis.

Outro processo sociotécnico possível é quando uma novidade é incorporada pelo regime sociotécnico vigente e passa a incrementá-lo, de forma que são "engolidas" por ele e não possuem mais potencial de transformação sociotécnica. Ou ainda, um terceiro caminho é a sua "morte prematura", pois os processos de inovação são permeados por contradições e incertezas, uma vez que nem sempre as experimentações nos nichos geram novidades viáveis, como 
"sementes da transição" para novos processos tecnológicos e de desenvolvimento rural e regional, como Ploeg et al. (2004) as chamaram. Esta dinâmica das novidades nos nichos pode ser observada na parte inferior da Figura 1.

A PMN também postulou um novo modo de definir e pensar as formas de inovação, por isso resolveu chamá-lo de novidades, diferentemente do conceito clássico de inovação. As novidades surgem de "baixo para cima", são novas maneiras que os atores sociais encontram para conduzir e modificar suas vidas. As novidades são criadas a partir de conhecimentos hibridizados e têm caráter radical perante o regime sociotécnico vigente, uma vez que visam a modificá-lo e surgem não respeitando as regras tecnológicas já preexistentes (LONG, 2006). Além disso, as novidades são internas aos locais, posto que surgem com base nos elementos sociotécnicos do próprio território (WISKERKE; PLOEG, 2004).

Conforme afirmam Roep e Wiskerke (2004), as novidades podem ser de vários tipos (um novo conhecimento, novos produtos e processos, nova rede social, forma de se organizar, novas tecnologias, novos mercados, etc.), podem gerar efeitos diferentes (aumento da renda das experiências, melhor qualidade de vida, ampliação de vendas nos mercados), formam redes sociotécnicas (associações, cooperativas, redes tecnológicas, sociais) e possuem efeitos diversos sobre os atores sociais e os processos de desenvolvimento rural e regional (aumento da autonomia, do grau de sustentabilidade ambiental, economia mais circular, etc.).

No presente estudo as práticas inovadoras estudadas estão de acordo com as formas de inovação apresentadas pela PMN, por isso foram chamadas de novidades. A noção de novidades foi importante na compreensão de como são criadas novas tecnologias no âmbito da produção agroindustrial familiar, quais processos de interfaces sociais estão envolvidos, quais conhecimentos e circunstâncias foram catalisadores dos processos criativos e quais transições sociotécnicas estão sendo viabilizadas pelas novidades.

No Brasil a PMN e a noção de novidades já foram utilizadas em pesquisas. Relata-se na sequência os resultados de alguns dos principais estudos e setores, sem querer exaurir toda a literatura existente. As primeiras análises aplicadas são de Maques (2009) e Mello (2009). Marques (2009), ao analisar o setor de plantas medicinais ecológicas ressaltou haver intensas novidades e potencialidade para o estabelecimento de um nicho de inovação, devido ao fato de existirem processos ativos de articulação de aprendizagens entre atores e de redes sociais. A autora ainda menciona que a maior vulnerabilidade do nicho sociotécnico analisado é a falta de alinhamento de expectativas entre atores envolvidos, devido às barreiras colocadas pelo regime da agricultura moderna.

Já Mello (2009), em estudo no oeste catarinense, analisou as novidades organizacionais dos agricultores familiares, encontrando três tipos: cooperativismo de comercialização de leite, experiências agroecológicas com cadeias curtas e processos de agregação de valor em agroindústrias individuais e em redes. Mello ressaltou a dificuldade das novidades para se sedimentarem devido à necessidade de criação de alianças entre atores sociais de modo a formar um ambiente institucional mais favorável à construção das novidades.

Já Bulhões (2011), analisando sistemas agroflorestais por citricultores ecológicos no Vale do Caí, no Rio Grande do Sul, referiu que há a formação de um nicho tecnológico. Neste, foram observados relações de amizade e parentesco, valores culturais, informações, artefatos, técni- 
cas e práticas, destacando-se que a combinação de todos estes elementos é que constrói os diferentes tipos de conhecimentos utilizados. A autora ainda relata a existência de novidades tecnológicas que incluem várias combinações de espécies, densidades e a experimentação de diferentes técnicas de manejo dos citrus e das outras espécies nos sistemas agroflorestais, incluindo o desenvolvimento e adaptações em equipamentos.

Oliveira (2014) investigou as novidades nos agricultores ecológicos da Serra Gaúcha. As novidades identificadas foram o biofertilizante Super Magro e o uso da calda bordalesa. A autora observou a formação de uma teia de novidades, que foi responsável por uma nova onda de inovações, entre as quais foram observadas novas técnicas de cultivo, insumos produtivos, equipamentos, mudanças na legislação de alimentos, novos produtos processados, canais de comercialização, criação de associações e grupos de agricultores ecologistas.

Nesta mesma direção, a pesquisa de Lovatel (2018), no extremo oeste catarinense junto a produtores de leite orgânico, encontrou como resultados que os mesmos desenvolvem novidades em técnicas, processos e na sustentabilidade ambiental. Por meio dos seus conhecimentos fazem modificações e criam novos produtos, formas de manejar o agroecossistema, acessam novos canais curtos e formam uma nova rede social de atores que mobilizam instituições regionais. Como entraves ao desenvolvimento das novidades, a autora relata que estas não conseguiram sair do nicho sociotécnico, a pouca mobilização dos atores regionais e os mercados restritos que o leite orgânico possui para viabilizar seu scale up.

\section{ORIGENS E NOVIDADES CONSTRUÍDAS NAS UNIDADES PRODUTIVAS E AGROINDÚSTRIAS FAMILIARES}

Nesta seção apresenta-se e analisa-se os principais resultados da pesquisa de campo. Ela foi dividida em duas subseções, observando-se que na primeira discute-se as motivações das famílias para iniciarem suas agroindústrias e as mudanças ocorridas na sua renda agrícola. $\mathrm{Na}$ segunda seção analisa-se os diferentes tipos de novidades multidimensionais surgidos nas unidades de produção e nas agroindústrias, bem como seus efeitos nos processos de desenvolvimento rural e regional.

\section{Motivações para agroindustrialização}

Segundo as famílias estudadas, antes de iniciar as atividades de transformação de alimentos elas possuíam produções agrícolas em pequena escala, rendas agropecuárias baixas, com pouca ou nenhuma autonomia sobre suas produções (na maioria de grãos e commodities), mercados restritivos para o escoamento da produção e com dificuldades de reprodução social diante da realidade vivida dentro dos padrões da agricultura moderna.

Nestes padrões de produção anteriores essas famílias não tinham expectativas de futuro, isso porque a renda gerada, em três das quatro unidades de produção estudadas, estava abaixo do salário mínimo nacional (SM - salário mínimo por ocasião da pesquisa era de $\mathrm{R} \$ 954,00$ ). Na Tabela 1 é possível observar a renda bruta agrícola e o equivalente em salários mínimos 
por pessoa nos quatro casos antes da criação das agroindústrias. ${ }^{4} \mathrm{~A}$ pesquisa revela que a renda bruta total média era de 6,6 salários/mês/família. Salienta-se que cada família possui 4,75 membros em média, entre: crianças, jovens, adultos e idosos.

Tabela 1 - Renda bruta anual e mensal e sua comparação com o valor do salário mínimo antes da criação da agroindústria familiar

\begin{tabular}{lcccc}
\hline AGFs & $\begin{array}{c}\text { Renda Bruta por } \\
\text { ano (R\$) }\end{array}$ & $\begin{array}{c}\text { Renda Bruta por } \\
\text { mês (R\$) }\end{array}$ & $\begin{array}{c}\text { Número de } \\
\text { membros }\end{array}$ & $\begin{array}{c}\text { Salário per capita } \\
\text { (R\$) }\end{array}$ \\
\hline C1 & $248.720,40$ & $20.726,70$ & 9 & $2.302,96$ \\
C2 & $25.995,00$ & $2.166,25$ & 4 & 541,56 \\
C3 & $25.548,00$ & $2.129,00$ & 4 & 532,25 \\
C4 & $3.597,00$ & 299,75 & 2 & 149,87 \\
\hline Média & $\mathbf{7 5 . 9 6 5 , 1 0}$ & $\mathbf{6 . 3 3 0 , 4 2}$ & $\mathbf{4 , 7 5}$ & $\mathbf{8 8 1 , 6 6}$ \\
\hline
\end{tabular}

Fonte: Pesquisa de campo (2018).

Comparativamente, a agroindústria C4 possui uma renda bruta menor, muito devido ao esvaziamento da sua força de trabalho quando todos os filhos tornaram-se ausentes para trabalhar na cidade ou em outra unidade de produção. ${ }^{5}$ Apenas o caso $\mathrm{C} 1$ alcançava SM per capita maior que o salário mínimo brasileiro, de $\mathrm{R} \$ 2.302,96$ conforme a Tabela 1 . Os membros da família, no entanto, não estavam satisfeitos com a baixa autonomia que possuíam na unidade e com as práticas insustentáveis da agricultura modernizada.

Por meio da pesquisa foi possível relacionar informações para traçar uma trajetória histórica vivenciada pelos casos estudados. Cada experiência de agroindústria familiar possui uma data de fundação diferente, algumas mais antigas e outras mais recentes. A agroindústria familiar mais antiga é a C1, desde 1993, e a mais jovem é a C3, que surgiu no ano de 2006. Mesmo com trajetórias evolutivas distintas, os históricos das agroindústrias possuem similaridades que merecem ser detalhadas e analisadas. Uma das grandes características comuns é a criação da agroindústria como caminho de fuga da modernização da agricultura e permanência no campo, mas também devem ser consideradas questões de afeto, tradições familiares, satisfação pessoal, renda, sustentabilidade, entre outras.

Para sintetizar os aspectos multidimensionais das motivações relatadas pelos agricultores para criar suas AGFs, elas foram agrupadas no Quadro 2, de acordo com cada caso investigado. Nos casos estudados elenca-se diferentes motivos relatados para o surgimento da produção agroindustrial e para a permanência na atividade. As motivações foram agrupadas em três grupos: sociais, econômicos e ambientais.

\footnotetext{
${ }^{4}$ No trabalho explora-se a renda bruta das famílias, pois estas foram captadas a partir das entrevistas semiestruturadas, em que cada família declarou sua renda. Não foi aplicado nenhum método de cálculo econômico da renda, em que se poderia obter outros indicadores importantes, por exemplo, em torno da renda líquida das famílias e dos custos de produção.

${ }^{5}$ Estas rendas não agrícolas eram advindas da pluriatividade familiar. Além da renda agrícola, as famílias complementavam sua renda com atividades fora dos espaços rurais e também vendiam seu trabalho para vizinhos. Neste trabalho, não se levantou os valores dessas rendas.
} 
Quadro 2 - Motivações multidimensionais que levaram as famílias a criarem a agroindústria

\begin{tabular}{|c|c|c|c|}
\hline AGF & Social & Econômico & Ambiental \\
\hline $\mathrm{C} 1$ & $\begin{array}{l}\text { - Iniciativa do patriarca que, quando } \\
\text { aposentado, decidiu se dedicar às práticas } \\
\text { antigas de sustento; } \\
\text { - Manutenção das tradições e da história } \\
\text { familiar; } \\
\text { - Possibilitar a permanência no campo através } \\
\text { da sucessão familiar; } \\
\text { - Bem-estar na propriedade; } \\
\text { - Respirar ar puro; } \\
\text { - Saúde mental; } \\
\text { - Construção de conhecimentos; } \\
\text { - Autonomia de comercialização; } \\
\text { - Carinho pela atividade. }\end{array}$ & $\begin{array}{l}\text { - Elevar a renda; } \\
\text { - Diversificar a } \\
\text { produção. }\end{array}$ & $\begin{array}{l}\text { - Manutenção da } \\
\text { paisagem; } \\
\text { - Proteção de } \\
\text { fontes. }\end{array}$ \\
\hline C2 & $\begin{array}{l}\text { - Satisfação pessoal; } \\
\text { - Satisfação em produzir alimentos limpos; } \\
\text { - Proporcionar oportunidade de renda aos } \\
\text { filhos; } \\
\text { - Acesso a bens de consumo; } \\
\text { - Qualidade de vida; } \\
\text { - Aprendizado, conhecimentos; } \\
\text { - Gosto pela produção orgânica. }\end{array}$ & $\begin{array}{l}\text { - Diversificar a } \\
\text { produção; } \\
\text { - Elevar a renda. }\end{array}$ & $\begin{array}{l}\text { - Proteção do meio } \\
\text { ambiente; } \\
\text { - Proteção das } \\
\text { fontes de água; } \\
\text { - Promover o } \\
\text { equilíbrio natural. }\end{array}$ \\
\hline C3 & $\begin{array}{l}\text { - Acesso ao curso técnico, conhecimento; } \\
\text { - Incentivo da prefeitura municipal para } \\
\text { plantio da cultura frutífera; } \\
\text { - Autonomia na comercialização; } \\
\text { - Cursos de capacitação dados pelo Centro de } \\
\text { Apoio e Promoção da Agroecologia (Capa), } \\
\text { Prefeitura Municipal, Cresol e UTFPR; } \\
\text { - Qualidade de vida: satisfação, acesso a bens } \\
\text { de consumo; } \\
\text { - Saúde. }\end{array}$ & $\begin{array}{l}\text { - Elevar a renda; } \\
\text { - Diversificar a } \\
\text { produção. }\end{array}$ & $\begin{array}{l}\text { - Menor agressão } \\
\text { ao meio } \\
\text { ambiente; } \\
\text { - Maior equilíbrio } \\
\text { da natureza; } \\
\text { - Melhora da } \\
\text { qualidade do solo; } \\
\text { - Longevidade } \\
\text { da família e da } \\
\text { produção. }\end{array}$ \\
\hline C4 & $\begin{array}{l}\text { - Manutenção da tradição; } \\
\text { - Aprendizado com experimentação; } \\
\text { - Possibilidade de fazer investimentos para a } \\
\text { família; } \\
\text { - Acesso a bens de consumo; } \\
\text { - Novas amizades; } \\
\text { - Bem-estar na propriedade; } \\
\text { - Saúde; } \\
\text { - Independência da produção. }\end{array}$ & $\begin{array}{l}\text { - Maior } \\
\text { lucratividade } \\
\text { com menos } \\
\text { mão de obra; } \\
\text { - Menor } \\
\text { necessidade de } \\
\text { investimentos; } \\
\text { - Necessidade de } \\
\text { elevar a renda. }\end{array}$ & $\begin{array}{l}\text { - Preservação da } \\
\text { floresta; } \\
\text { - Equilíbrio natural; } \\
\text { - Manutenção da } \\
\text { paisagem; } \\
\text { - Proteção de } \\
\text { fontes. }\end{array}$ \\
\hline
\end{tabular}

Fonte: Pesquisa de campo (2018).

Os agricultores elencaram vários motivos sociais para a construção das agroindústrias, entre eles: a autonomia da família, acesso a novos conhecimentos, satisfação em produzir alimentos saudáveis e permanecer no campo. Além disso, as motivações ambientais também ti- 
veram expressão significativa. Os agricultores estavam buscando preservar o meio ambiente e ampliar seus níveis de sustentabilidade. Uma mãe entrevistada relatou orgulhosamente que estava produzindo "comida de verdade, comida limpa" (C2, Verê/PR, fevereiro/2018). Nenhuma das motivações, entretanto, superou a descrição dos agricultores acerca do êxito econômico dos empreendimentos, que passaram a responder pela maior parte da renda da família.

A Tabela 2 apresenta a renda das famílias, após a instalação da agroindústria em suas unidades de produção. É possível observar o aumento da renda bruta obtida pelos agricultores, que em média aumentou $269,35 \%$. O caso C1 aumentou a renda bruta em $278,87 \%$ e o caso $C 4$ apresentou um aumento de $422,57 \%$. Estes dois casos foram os que tiveram maiores aumentos da renda bruta (nestes dados estão somadas somente as rendas agrícolas e agroindustriais). ${ }^{6}$

Tabela 2 - Aumento percentual de renda bruta após a instalação das agroindústrias familiares

\begin{tabular}{ccccc}
\hline AGFs & C1 & C2 & C3 & C4 \\
\hline $\begin{array}{c}\text { Renda bruta antes das AGFs } \\
\text { (R\$/ano) }\end{array}$ & $248.720,40$ & $25.995,00$ & $25.548,00$ & $3.597,00$ \\
$\begin{array}{c}\text { Renda bruta depois das AGFs } \\
\text { (R\$/ano) }\end{array}$ & $693.630,00$ & $67.120,00$ & $42.500,00$ & $15.200,00$ \\
\hline $\begin{array}{c}\text { Aumento percentual da Renda } \\
\text { Bruta (\%) }\end{array}$ & $\mathbf{2 7 8 , 8 7}$ & $\mathbf{2 5 8 , 2 0}$ & $\mathbf{1 6 6 , 3 5}$ & $\mathbf{4 2 2 , 5 7}$ \\
\hline
\end{tabular}

Fonte: Pesquisa de campo (2018).

Observando a média, é possível constatar que as famílias quase triplicaram a renda após a criação de suas agroindústrias em um espaço de tempo que foi diferente entre os casos, por exemplo, a agroindústria mais antiga possui 22 anos de trajetória, enquanto a mais jovem tem apenas 7 anos. $O$ aumento de renda bruta, em todos os quatro casos pesquisados, permitiu sedimentar a estratégia de agroindustrialização nas famílias e melhorar sua qualidade de vida.

\section{Novidades multifacetadas e seus resultados}

Esta seção apresenta e discute os diferentes tipos de novidades encontradas na pesquisa de campo. Um exemplo de novidade produtiva muito representativa do Quadro 3, que foi identificada a campo, é o vinho canônico, desenvolvido pelo C1. A bebida agrega conhecimentos tácitos, científicos e contextuais. A ideia de criá-lo chegou até a agroindústria trazida por um dos filhos do idealizador, que é padre. Assim, iniciaram os testes e experimentações para desenvolver o próprio vinho canônico que teria um novo público e um preço de venda mais elevado. 0 agricultor afirmou que "o vinho canônico é um diferencial porque não tem em qualquer lugar" (C1, Verê/PR, fevereiro/2018), demonstrando o potencial da bebida enquanto novidade.

As novidades produtivas podem ser novos produtos/processos ou a variação de produtos/alimentos já existentes e contribuem para a autonomia financeira do agricultor familiar. Um alimento diferenciado pode ser produzido numa escala menor porque mesmo assim a renda será satisfatória (agrega mais valor por unidade) e a agroindústria passa a depender

\footnotetext{
${ }^{6}$ A renda computada para a análise nesta tabela desconsidera rendas não agrícolas, tais como aposentadorias, pensões, atividades rurais não agrícolas, pluriatividade e rendas obtidas em outras atividades. Foram consideradas apenas rendas provenientes da comercialização de alimentos processados (queijos, vinhos, geleias, suco, entre outros) e de venda de matérias primas (uva, leite, frutas, grãos, etc.) declaradas pelos agricultores.
} 
mais da sua capacidade de produzir alimentos com qualificações alimentares específicas do que produzir em escala, para ter viabilidade técnica e financeira, como descrito por Niederle (2013).

Quadro 3 - Tipos de novidades e resultados gerados nas unidades de produção e nas agroindústrias familiares

\begin{tabular}{|c|c|c|c|c|}
\hline AGFs & Novidades & $\begin{array}{c}\text { Tipo de } \\
\text { novidade }\end{array}$ & Em que consistem & Principais processos inventivos \\
\hline $\mathrm{C} 1$ & $\begin{array}{l}\text { Vinho canô- } \\
\text { nico }\end{array}$ & Produtiva & $\begin{array}{l}\text { Produção de vinho } \\
\text { conforme a aceitação } \\
\text { de consumo da Igreja } \\
\text { Católica. }\end{array}$ & $\begin{array}{l}\text { - Adequação da receita; } \\
\text { - Adequação da forma de produzir visan- } \\
\text { do sabor, textura, cor e teor alcoólico } \\
\text { adequados; }\end{array}$ \\
\hline $\mathrm{C} 1$ & $\begin{array}{l}\text { Espaçamen- } \\
\text { to diferen- } \\
\text { ciado entre } \\
\text { plantas }\end{array}$ & Tecnológica & $\begin{array}{l}\text { Estabelecimento de } \\
\text { um espaço diferente } \\
\text { entre as plantas de } \\
\text { videira }\end{array}$ & $\begin{array}{l}\text { - Adequação do espaçamento de plantio } \\
\text { para } 2,5 \text { × } 2,5 \mathrm{~m} \text {, considerando o ma- } \\
\text { quinário utilizado, entrada de luz solar, } \\
\text { adubação e produtividade; } \\
\text { - Rearranjo do plantio para não reduzir o } \\
\text { número de plantas; } \\
\end{array}$ \\
\hline C1 e C4 & $\begin{array}{l}\text { Produção } \\
\text { própria de } \\
\text { mudas }\end{array}$ & Tecnológica & $\begin{array}{l}\text { Produção das mudas } \\
\text { que são cultivadas } \\
\text { para produção da } \\
\text { matéria prima das } \\
\text { agroindústrias }\end{array}$ & $\begin{array}{l}\text { - Composição de um substrato adequado; } \\
\text { - Formação das mudas por meio de par- } \\
\text { tes das plantas adultas já cultivadas; } \\
\text { - Transplante de mudas com taxa de so- } \\
\text { brevivência satisfatória; }\end{array}$ \\
\hline $\begin{array}{c}\mathrm{C} 2, \mathrm{C} 3 \mathrm{e} \\
\mathrm{C} 4\end{array}$ & $\begin{array}{l}\text { Cultivo Or- } \\
\text { gânico }\end{array}$ & Tecnológica & $\begin{array}{l}\text { Produção de matérias } \\
\text { primas como: leite, } \\
\text { cana- de-açúcar, fru- } \\
\text { tas e olerícolas orgâ- } \\
\text { nicas. }\end{array}$ & $\begin{array}{l}\text { - Utilização de produtos regulamentados } \\
\text { pela legislação de produtos orgânicos; } \\
\text { - Manejo de pragas e doenças mediante } \\
\text { rotação de culturas e cultivo misto; } \\
\text { - Utilização de insumos resultantes do } \\
\text { próprio sistema (adubo, sementes, fito- } \\
\text { terápicos, grãos, etc.); } \\
\text { - Isolamento da propriedade por meio de } \\
\text { barreiras vegetais; }\end{array}$ \\
\hline C4 & $\begin{array}{l}\text { Aquecimen- } \\
\text { to ideal em } \\
\text { fornalha }\end{array}$ & Tecnológica & $\begin{array}{l}\text { Conhecer a lenha } \\
\text { correta para uso em } \\
\text { fornalha e técnicas } \\
\text { familiares de controle } \\
\text { do fogo na hora da } \\
\text { transformação do cal- } \\
\text { do de cana em açúcar } \\
\text { mascavo } \\
\end{array}$ & $\begin{array}{l}\text { - Coleta e replantio de árvores que são } \\
\text { ideais para aquecimento da fornalha; } \\
\text { - Conhecimento tácito herdado dos ante- } \\
\text { cessores familiares para manutenção da } \\
\text { temperatura do fogo; }\end{array}$ \\
\hline $\mathrm{C} 1$ & $\begin{array}{l}\text { Produção } \\
\text { agrícola em } \\
\text { organização } \\
\text { familiar co- } \\
\text { letivizada }\end{array}$ & $\begin{array}{l}\text { Organizacio- } \\
\text { nal }\end{array}$ & $\begin{array}{l}\text { Convívio entre quatro } \\
\text { diferentes grupos } \\
\text { familiares na mesma } \\
\text { propriedade rural e } \\
\text { produção conjunta }\end{array}$ & $\begin{array}{l}\text { - Organização de pessoas para o trabalho; } \\
\text { - Divisão das atividades conforme as ha- } \\
\text { bilidades individuais; } \\
\text { - Organização do custeio das despesas } \\
\text { familiares; } \\
\text { - Organização da aquisição e utilização } \\
\text { dos bens comuns (carros, casas, máqui- } \\
\text { nas, etc.) }\end{array}$ \\
\hline
\end{tabular}




\begin{tabular}{|c|c|c|c|c|}
\hline $\mathrm{C} 2$ & $\begin{array}{l}\text { Cozinha } \\
\text { coletiva }\end{array}$ & $\begin{array}{l}\text { Organizacio- } \\
\text { nal }\end{array}$ & $\begin{array}{l}\text { Cozinha coletiva para } \\
\text { uso de diferentes } \\
\text { grupos de agriculto- } \\
\text { res agroecológicos } \\
\text { na transformação de } \\
\text { alimentos }\end{array}$ & $\begin{array}{l}\text { - Espaço físico e equipamentos adquiri- } \\
\text { dos por intermédio do Capa; } \\
\text { - Uso coletivo do espaço físico no pro- } \\
\text { cessamento de alimentos (conservas e } \\
\text { geleias); } \\
\text { - Agregação de valor por meio da trans- } \\
\text { formação dos alimentos; } \\
\text { - Comercialização via Coopervereda. }\end{array}$ \\
\hline $\mathrm{C} 2$ e $\mathrm{C} 3$ & $\begin{array}{l}\text { Certificação } \\
\text { orgânica } \\
\text { participa- } \\
\text { tiva }\end{array}$ & $\begin{array}{l}\text { Organizacio- } \\
\text { nal }\end{array}$ & $\begin{array}{l}\text { Certificação orgânica } \\
\text { participativa por meio } \\
\text { da Rede Ecovida e do } \\
\text { Capa }\end{array}$ & $\begin{array}{l}\text { - Adequação das práticas produtivas para } \\
\text { atender às regras da produção orgânica; } \\
\text { - Inclusão dos agricultores no grupo de } \\
\text { certificação; } \\
\text { - Agregação de valor nos alimentos da } \\
\text { agricultura familiar; }\end{array}$ \\
\hline $\mathrm{C} 2$ e C3 & $\begin{array}{l}\text { Comercia- } \\
\text { liza-ção via } \\
\text { Cooperve- } \\
\text { reda }\end{array}$ & $\begin{array}{l}\text { Organizacio- } \\
\text { nal }\end{array}$ & $\begin{array}{l}\text { Venda de alimentos } \\
\text { por meio da coope- } \\
\text { rativa }\end{array}$ & $\begin{array}{l}\text { - Organização e otimização da produção } \\
\text { de alimentos nas propriedades da agri- } \\
\text { cultura familiar; } \\
\text { - Acesso a novos mercados pelos agricul- } \\
\text { tores familiares; } \\
\text { - Venda para consumidores locais por } \\
\text { meio da loja própria, licitações munici- } \\
\text { pais e programas governamentais (Pro- } \\
\text { grama de Aquisição de Alimentos (PAA) } \\
\text { e Programa Nacional de Alimentação } \\
\text { Escolar (Pnae). }\end{array}$ \\
\hline C1 e C3 & $\begin{array}{l}\text { Organiza- } \\
\text { ção de um } \\
\text { passeio } \\
\text { pelo roteiro } \\
\text { turístico } \\
\text { "Caminhos } \\
\text { do Verê" }\end{array}$ & $\begin{array}{l}\text { Organizacio- } \\
\text { nal }\end{array}$ & $\begin{array}{l}\text { Circuito de turismo } \\
\text { rural e ecológico no } \\
\text { município }\end{array}$ & $\begin{array}{l}\text { - Oferta de ônibus e guia turístico para os } \\
\text { turistas interessados; } \\
\text { - Passeio no roteiro turístico “Caminhos } \\
\text { do Verê"; } \\
\text { - Comercialização de alimentos e artesa- } \\
\text { natos durante as visitas; } \\
\text { - Aproximação entre agricultores e con- } \\
\text { sumidores; } \\
\text { - Marketing das agroindústrias familiares. }\end{array}$ \\
\hline $\begin{array}{c}\mathrm{C2}, \mathrm{C} 3 \mathrm{e} \\
\mathrm{C} 4\end{array}$ & $\begin{array}{l}\text { Cultivo or- } \\
\text { gânico }\end{array}$ & $\begin{array}{l}\text { Tecnológica } \\
\text { e ambiental }\end{array}$ & $\begin{array}{l}\text { Produção de maté- } \\
\text { rias primas como: } \\
\text { leite, cana-de-açúcar, } \\
\text { frutas e olerícolas } \\
\text { orgânicas }\end{array}$ & $\begin{array}{l}\text { - Utilização de produtos regulamentados } \\
\text { pela legislação de produtos orgânicos; } \\
\text { - Uso de cobertura verde; } \\
\text { - Manejo de pragas e doenças mediante } \\
\text { rotação de culturas e cultivo misto; } \\
\text { - Utilização de insumos resultantes do } \\
\text { próprio sistema (adubo, sementes, fito- } \\
\text { terápicos, grãos, etc.); } \\
\text { - Isolamento da propriedade por meio de } \\
\text { barreiras vegetais; } \\
\end{array}$ \\
\hline $\begin{array}{l}\text { C1, C2, } \\
\text { C3 e C4 }\end{array}$ & $\begin{array}{l}\text { Manu- } \\
\text { tenção da } \\
\text { paisagem } \\
\text { natural }\end{array}$ & Ambiental & $\begin{array}{l}\text { Preservação de ele- } \\
\text { mentos que cons- } \\
\text { tituem a paisagem } \\
\text { natural e que reme- } \\
\text { tem às antigas práti- } \\
\text { cas rurais }\end{array}$ & $\begin{array}{l}\text { - Plantio de árvores e plantas; } \\
\text { - Instalação de roda d'água; } \\
\text { - Práticas de jardinagem na propriedade; } \\
\text { - Manutenção de instalações antigas; } \\
\text { - Manutenção da criação de animais sem } \\
\text { melhoramento genético; } \\
\text { - Cuidados com a estética da proprieda- } \\
\text { de; } \\
\text { - Exaltação de práticas antigas; } \\
\text { - Diversificação de plantas e animais na } \\
\text { propriedade; }\end{array}$ \\
\hline
\end{tabular}


Marcio Gazolla - Mariana Beal Dengo - Miguel Angelo Perondi

\begin{tabular}{|c|c|c|c|c|}
\hline $\begin{array}{l}\text { C1, C2, } \\
\text { C3 e C4 }\end{array}$ & $\begin{array}{l}\text { Proteção de } \\
\text { fontes de } \\
\text { água }\end{array}$ & Ambiental & $\begin{array}{l}\text { Proteção de } \\
\text { nascentes e riachos } \\
\text { que passam pelas } \\
\text { propriedades }\end{array}$ & $\begin{array}{l}\text { - Plantio de árvores; } \\
\text { - Controle de erosão; } \\
\text { - Uso de diferentes tipos de barreiras } \\
\text { contra contaminação da água (caixas, } \\
\text { plantas, tubos, etc.); }\end{array}$ \\
\hline $\mathrm{C} 1$ e $\mathrm{C} 2$ & $\begin{array}{l}\text { Roteiro } \\
\text { turístico } \\
\text { "Caminhos } \\
\text { do Verê" }\end{array}$ & $\begin{array}{l}\text { Mercadoló- } \\
\text { gica }\end{array}$ & $\begin{array}{l}\text { Levar os turistas até } \\
\text { as agroindústrias } \\
\text { familiares }\end{array}$ & $\begin{array}{l}\text { - Atração dos turistas que se hospedam } \\
\text { no Hotel Águas do Verê Termas para as } \\
\text { agroindústrias familiares do município; } \\
\text { - Organização e parceria entre as agroin- } \\
\text { dústrias, o hotel e a prefeitura ; } \\
\text { - Fidelização dos clientes após a visita; } \\
\text { - Aproximar os consumidores da agricul- } \\
\text { tura familiar em geral; } \\
\text { - Proporcionar lazer aos turistas que se } \\
\text { hospedam em Verê. }\end{array}$ \\
\hline C4 & $\begin{array}{l}\text { Entrega em } \\
\text { domicílio }\end{array}$ & $\begin{array}{l}\text { Mercadoló- } \\
\text { gica }\end{array}$ & $\begin{array}{l}\text { Entregar os alimentos } \\
\text { na casa dos consumi- } \\
\text { dores }\end{array}$ & $\begin{array}{l}\text { - Proporcionar comodidade aos consumi- } \\
\text { dores; } \\
\text { - Fidelizar os clientes; } \\
\text { - Criar laços de amizade; } \\
\text { - Possibilitar demanda constante de ali- } \\
\text { mentos. }\end{array}$ \\
\hline C1 e C4 & $\begin{array}{l}\text { Cadeias } \\
\text { curtas agro- } \\
\text { alimentar }\end{array}$ & $\begin{array}{l}\text { Mercadoló- } \\
\text { gica }\end{array}$ & $\begin{array}{l}\text { Venda de alimentos } \\
\text { processados pela } \\
\text { agroindústria familiar } \\
\text { diretamente na pro- } \\
\text { priedade rural }\end{array}$ & $\begin{array}{l}\text { - Proporcionar lazer e entretenimento } \\
\text { aos clientes; } \\
\text { - Aproximar os consumidores da agroin- } \\
\text { dústria familiar; } \\
\text { - Criar laços de amizade; } \\
\text { - Abrir a agroindústria para os consumi- } \\
\text { dores de maneira a ganhar credibilidade } \\
\text { nas questões relacionadas à qualidade } \\
\text { e higiene. }\end{array}$ \\
\hline
\end{tabular}

Fonte: Pesquisa de campo (2018).

Já as novidades tecnológicas permitem aos agricultores comprar menos insumos de fora da unidade de produção, por exemplo, gerando suas próprias mudas, criando atividades que geram resíduos orgânicos que possam ser reutilizados para adubação, fazendo caldas e produtos fitossanitários para o controle de pragas e doenças, garantindo o equilíbrio natural e elaborando as próprias práticas e técnicas de produção, a fim de reduzir a necessidade de técnicos (conhecimentos especializados) para conduzir e orientar o desenvolvimento das atividades.

No Quadro 3 também estão esquematizadas as novidades organizacionais que foram encontradas nas agroindústrias. As novidades que foram sendo criadas pela organização dos agricultores priorizaram potencializar a produção e a comercialização dos alimentos. A organização familiar coletiva do caso C1, a cozinha coletiva (C2) e a certificação orgânica participativa (C2 e C3) buscaram aperfeiçoar a produção de alimentos. Essas novidades deram condições aos agricultores para acessar novos conhecimentos, construir novos mercados, conseguir força de trabalho para a atividade, conduzir as atividades de processamento, técnicos para acompanhar a produção e viabilizar a comercialização formal dos alimentos (no caso da certificação orgânica). Os conhecimentos tácitos e contextuais foram construídos pelos próprios agricultores por inter- 
médio de trocas de experiências, aprendizados junto a outros atores sociais e internalizações de práticas sociotécnicas conforme já observado em outras pesquisas (STUIVER; LEEUWIS; PLOEG, 2004; BULHÕES, 2011; LOVATEL, 2018).

A organização entre diferentes atores sociais foi o meio encontrado pelos agricultores familiares para solucionar os problemas que enfrentavam, como a necessidade de: capital financeiro, acesso aos conhecimentos, organização e construção social de mercados consumidores, formalização e certificação orgânica. Conforme Ploeg et al. (2004), as novidades são novas práticas que se mostram superiores às já existentes, podendo ser, entre outras, uma nova organização social que possibilite a geração de novos mercados. As estratégias acionadas pelos agricultores dirigem-se neste sentido, uma nova forma de organização, que pode ser chamada, a partir do que traz a literatura, de novidades organizacionais, conforme Mello (2009) conclui em sua pesquisa no oeste catarinense.

Em outra dimensão, estes casos também apresentaram o que se costuma denominar de novidades ambientais, uma vez que elas têm a ver com execução de práticas sustentáveis (Quadro 3). Parte dos agricultores não lograram êxito com a produção de commodities em escala e ainda se sentiram prejudicados pelo aumento da carga de trabalho e pelas condições de insalubridade. $\mathrm{O}$ técnico T3 explicou que a preocupação dos agricultores familiares em preservar a natureza aumentava depois de observar os efeitos nocivos da abertura inadequada de áreas que antes eram protegidas ou devido aos problemas causados pelo uso dos agrotóxicos.

Nesse sentido, as agroindústrias familiares surgem como estratégias para driblar as condições impostas pelo regime sociotécnico alimentar "moderno", no intuito de construir alternativas ao padrão tecnológico hegemônico degradador dos recursos naturais. Assim, os agricultores passaram a criar novidades para melhorar as condições do meio ambiente $e$ dos locais onde estão inseridos e suas proximidades territoriais, corroborando os resultados de outras investigações já desenvolvidas no Brasil (MARQUES; 2009; OLIVEIRA, 2014).

Por exemplo, com o intuito de preservar a paisagem natural, surgem os projetos de preservação de nascentes e riachos, que são incentivados e em partes custeados pela prefeitura por meio da Secretaria da Agricultura. Os mesmos são operacionalizados da seguinte maneira: os agricultores, juntamente com um técnico, apresentam a intenção de preservar um córrego, nascente ou mata ciliar de um rio, sendo organizado um plano de ação local. O viveiro municipal fornece mudas de árvores necessárias e um técnico para auxiliar na execução do projeto. Assim, as novidades ambientais, por vezes, são também organizacionais, uma vez que dependem de outros atores para sua efetivação, em virtude da carência de recursos financeiros e/ou de conhecimentos que os agricultores apresentam.

Quando os agricultores foram questionados se as suas ações locais estariam impactando a preservação do meio ambiente em âmbito mundial, todos creem que sim, mencionando que "se cada um fizer um pouquinho" (C2, Verê/PR, fevereiro, 2018) os cuidados com a natureza aumentam significativamente e as famílias que iniciam a preservação em suas unidades também acabam influenciando e "servindo de exemplo para outras famílias" (C3, Verê/PR, fevereiro/2018).

As novidades ambientais estudadas são ainda mais vistas quando alguém, além de comprar um alimento e levar para diversos lugares (que é carregado de significados simbólicos), também fotografa uma agroindústria familiar ou a paisagem rural da unidade, durante a visita, e 
"manda para mil amigos" (C1, Verê/PR, fevereiro/2018) do Brasil e do exterior. Assim, é possível um turista e/ou consumidor mostrar as inovadoras alternativas encontradas pelos agricultores familiares dentro do nicho sociotécnico, num planeta em que globalização e a Internet permitem que as informações cheguem rapidamente a diversos locais. Estas novidades ambientais criadas inventivamente pelos agricultores em suas unidades e agroindústrias vão na direção do que a noção de novidades no desenvolvimento rural e regional apregoa, como um dos seus principais resultados: o aumento contínuo dos níveis de sustentabilidade ambiental das práticas dos atores, como outras investigações já mostraram internacionalmente e no Brasil (MOORS; RIP; WISKERKE, 2004; OLIVEIRA, 2014; GAZOLLA; SCHNEIDER, 2015).

Por fim, as experiências necessitam comercializar seus alimentos, criando novos canais de comercialização e mercados, que são caracterizados como novidades mercadológicas, conforme o Quadro 3. Antes da existência das agroindústrias, as famílias direcionavam as suas produções para quatro canais (cerealistas, laticínios, supermercados e cadeias curtas) que não possibilitavam autonomia na atribuição de preços, relações sociais eram assimétricas em razão do maior poder de barganha dos compradores nas regras dos contratos firmados, que beneficiavam os atores que realizavam as aquisições (exceção eram os canais curtos, que devido à comercialização ser na unidade de produção, mantinha-se sob o domínio dos agricultores).

Após a criação das agroindústrias foi possível observar aumento do número de canais para seis, além da comercialização feita pelas cooperativas que acessam o Programa de Aquisição de Alimentos (PAA), Programa Nacional de Alimentação Escolar (Pnae) e licitações municipais. A comercialização por meio de cadeias curtas agroalimentares já era realizada na região, isso porque as famílias que produziam excedentes normalmente vendiam aos vizinhos e conhecidos. Assim, cada família ofertava o que tinha produzido e também adquiria o que as outras famílias haviam produzido além das suas necessidades individuais. Nos casos estudados, as famílias geraram a novidade mercadológica, incluindo a produção de alimentos elaborados com qualificações alimentares específicas (artesanais, sustentáveis, da agricultura familiar, etc.) e obtiveram demandas maiores do que a produção já ofertada anteriormente, que foi escoada por cadeias curtas, segundo já referendado por outras pesquisas com agroindústrias (GAZOLLA; SCHNEIDER, 2015, 2017).

Dessa forma, vender alimentos diferenciados pelas agroindústrias familiares é uma novidade mercadológica, por romper com a rotina anterior, que era de vender matérias primas (grãos e commodities), por um preço baixo, para passar a comercializar alimentos com qualificações alimentares específicas e com maior nível de valor agregado e de preços. Esse movimento de qualificação alimentar nos mercados também provoca mudanças sociotécnicas nas famílias (acesso a bens materiais e conhecimentos, satisfação pessoal e aumento de renda), no meio ambiente (produção mais sustentável e consequente preservação do meio ambiente) e no desenvolvimento rural e regional (geração de renda, impacto na economia e comércio local e oferta de alimentos com aspectos nutricionais, sociais e culturais de acordo com os hábitos de consumo da população).

Além destas novidades, a pesquisa constatou a proeminência dos atores sociais em criar redes sociais de apoio às agroindústrias, como a rede territorial apresentada na Figura 2. A investigação revelou que a organização do sistema coletivo de produção familiar (Caso C1) e das cooperativas locais (Casos C3 e C2), sobretudo a articulação entre estas associações e os demais atores sociais envolvidos (prefeitura, Centro de Apoio e Promoção da Agroecologia (Capa), As- 
sociação de Estudos, Orientação e Assistência Rural (Assesoar), Sistema de Cooperativas de Crédito Rural com Interação Solidária (Cresol), entre outros, foi determinante para a consolidação das práticas agroindustriais que já vinham sendo desenvolvidas dentro das unidades produtivas.

Além disso, observou-se que mesmo com distintas organizações, muitas vezes os agricultores participantes repetem-se em razão da atividade agroindustrial ser o fio condutor dos processos de desenvolvimento rural municipal. Existe um grupo de agricultores que fez parte de diferentes processos organizacionais e institucionais, no intuito de abrir caminhos para a produção agroindustrial no município. Por exemplo, o agricultor do caso C3 participou como agente de desenvolvimento do Capa, foi também cooperado da Cooperativa de Produtos Orgânicos e Agroecológicos do Sudoeste do Paraná (Coopervereda) e membro da Cooperativa de Suco dos Vitivinicultores de Verê (Coopervive), evidenciando a noção de agência dos atores sociais (proatividade de suas ações), como formulou Long (2006).

Dentro da rede de atores sociais criada (Figura 2), cada integrante tem uma função que não é equivalente às obrigações dos demais, isso porque cada um age dentro das suas condições de agência. Como descreve Long (2006), ao afirmar que cada ator social exerce sua pro-atividade dentro das capacidades e conhecimentos que possui, sendo a organização de diferentes atores em rede, agrega e direciona as ações do grupo social em prol de um objetivo comum, que é o fortalecimento das novidades geradas nas agroindústrias familiares.

Analisando a rede social mais profundamente, verifica-se que os casos C1, C2, e C3 relacionam-se com um maior número de atores sociais. Os casos $\mathrm{C} 2$ e $\mathrm{C} 3$ se relacionam diretamente com atores em comum (Capa, UTFPR, Rede Ecovida e prefeitura) e também estão participando na mesma cooperativa (Coopervereda). Todos os casos estudados relacionam-se com os consumidores, mas a pesquisa mostrou que os consumidores não são os mesmos e nem possuem as mesmas características sociais.

$\mathrm{O}$ caso $\mathrm{C} 4$ depende apenas dos seus consumidores para viabilizar suas vendas, com esse grupo de consumidores sendo formado pelos amigos e familiares. É um grupo fiel que compra os alimentos baseado na amizade e na confiança. $\mathrm{O}$ agricultor explica que os consumidores "compram para ajudar e a gente que trabalha para alimentar eles com uma comida boa" (C4, Verê/PR, fevereiro/2018). Os demais casos (C1, C2 e C3) acessam diferentes grupos de consumidores (turistas, amigos, pessoas preocupadas com a rastreabilidade dos alimentos e a sustentabilidade da produção, consumidores preocupados com a saúde, longevidade, ativistas ambientais, entre outros).

O caso C1 também se relaciona com a prefeitura e suas Secretarias, mas participa de outra cooperativa denominada Cooperativa Regional dos Vitivinicltores do Sudoeste do Paraná (Coopervin), mesmo produzindo um tipo de bebida em comum com o caso C3 (suco de uva). 0 caso C1 não se relaciona com a Coopervive. Este caso também vende uva in natura nos supermercados, mas não comercializa na loja da Coopervereda e, ainda, produz geleias sem se relacionar com a cozinha industrial coletiva do Capa.

Por meio da pesquisa foi possível perceber que esse distanciamento ocorre devido ao fato de os agricultores que se relacionam com o Capa participam de um grupo atuante que interfere diretamente nas atividades da Coopervive e da Coopervereda, concomitantemente. As ligações presentes na rede e a ausência instigante das mesmas (caso $\mathrm{C} 1$ ) expressam as tensões entre os atores sociais e as suas disputas em torno das relações de poder, que mesmo em rede, ocorrem e são assimétricas. 
Figura 2 - Rede territorial de atores sociais envolvidos na produção de novidades e alimentos das agroindústrias familiares

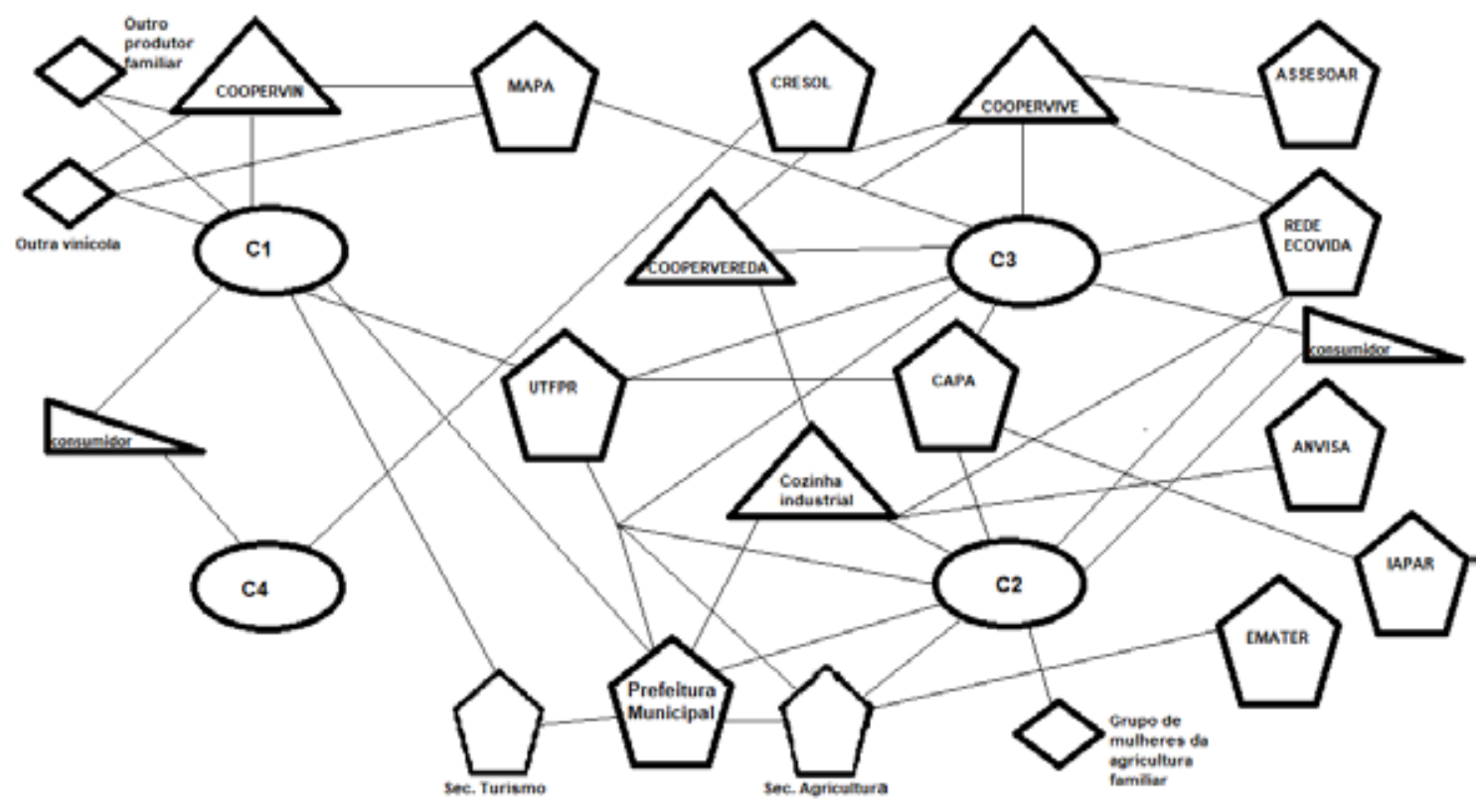

Fonte: Pesquisa de campo (2018).

A rede social e territorial de atores é considerada uma novidade organizacional, pois preenche as seguintes características que a literatura sobre novidades congrega (WISKERKE; PLOEG, 2004; MARQUES, 2009; LOVATEL, 2018): a) os atores interagem entre si e compartilham perspectivas territoriais comuns futuras em torno da agroindustrialização; b) apoiam-se organicamente para ganhar escala produtiva e comercial local e regional; c) buscam aumentar seu poder e influências, especialmente em relação ao Estado e às políticas públicas (principalmente no cenário de crise econômica e institucional do país).

Outra novidade mercadológica é em relação ao número de canais de comercialização, que foram ampliados com as agroindústrias, acessando supermercados locais, bares, entrega em domicílio, conforme a Figura 3. O canal que oferece maior autonomia aos agricultores na definição de preços é a venda direta na unidade (que escoa $33 \%$ da produção, sendo praticada por todas as agroindústrias estudadas). Neste canal cada agricultor consegue colocar preço nos seus alimentos, possuindo gestão própria das vendas e maiores graus de autonomia em relação à produção e distribuição dos alimentos. É também por meio das cadeias curtas que os aspectos sociais, culturais e ambientais dos alimentos e do local passam a ser valorizados pelos consumidores. Como autonomia e sustentabilidade são os dois principais resultados esperados pelos agricultores que criam novidades, a ampliação dos canais que garantem essas condições é essencial para a melhoria da renda e da qualidade de vida das famílias do campo, conforme estudos das novidades em mercados têm ressaltado na literatura (MELLO, 2009; GAZOLLA, 2020).

Atualmente nenhum agricultor vende diretamente ao PAA e Pnae, mas o fazem por meio das cooperativas, como é possível observar no gráfico à esquerda da Figura 3, em que estão os canais que os agricultores acessam. No gráfico à direita é possível observar os canais de comercialização acessados pelas cooperativas, no qual é notável a importância desses programas governamentais para a comercialização de alimentos da agricultura familiar. O Pnae é o progra- 
ma que recebe maior quantidade de alimentos comercializados pelas agroindústrias familiares, $63 \%$ dos alimentos vendidos via cooperativas são destinados a esse canal. Nos mercados institucionais os preços são estabelecidos no momento da compra de alimentos (fixados no ano pelo Estado) e, em muitas situações, superiores aos dos mercados regionais e locais. ${ }^{7}$

Figura 3 - Representação dos diferentes canais de comercialização construídos pelos agricultores familiares

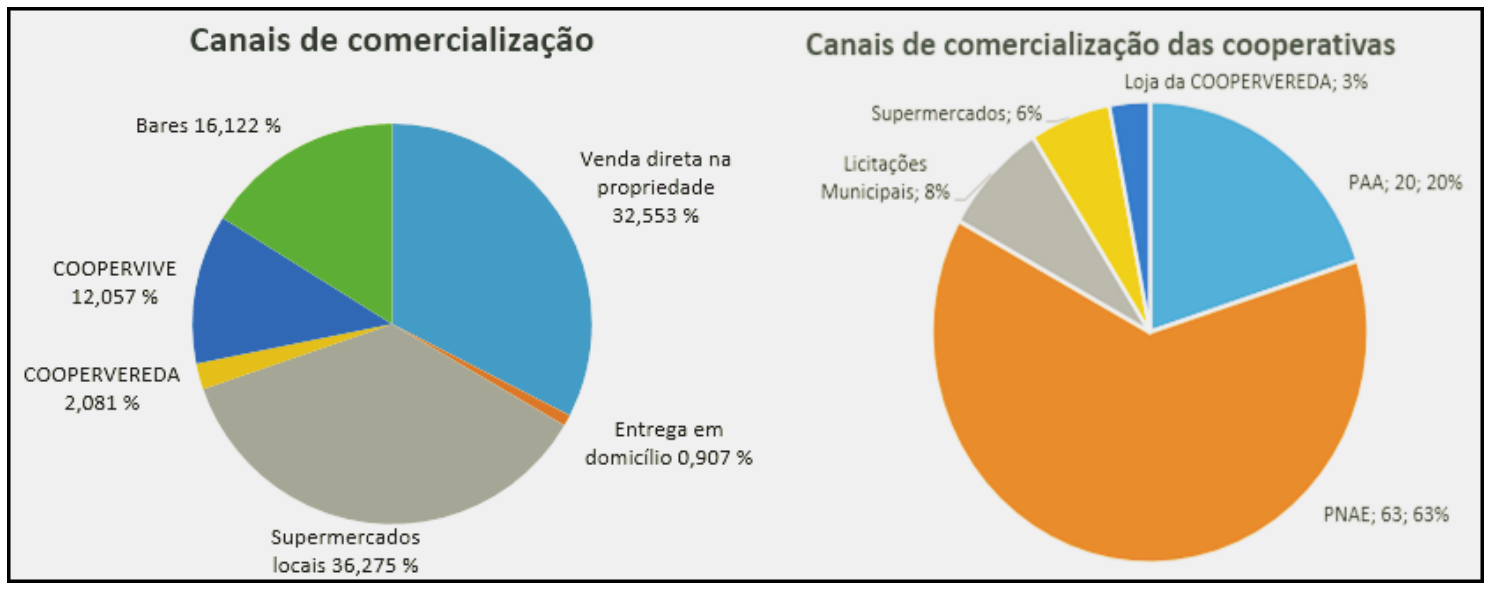

Fonte: Pesquisa de campo (2018).

A dependência dos agricultores e das cooperativas aos programas governamentais, no entanto, coloca em risco a estabilidade da comercialização de alimentos e o futuro de suas agroindústrias. A redução ou a extinção desses programas interfere em $14 \%$ da comercialização dos casos estudados. Quando se trata de cooperativas, essa interferência é ainda maior, com potencial de prejudicar até $83 \%$ da comercialização via PAA e Pnae (Figura 3). Hipoteticamente, se as licitações municipais também fossem suspensas/extintas, as cooperativas perderiam mais $8 \%$ das vendas. A dependência das políticas públicas que os agricultores e as cooperativas sofrem diante dessas formas de comercialização pode acabar rompendo com a sustentação financeira das agroindústrias e do conjunto de suas novidades construídas.

Uma importante estratégia que acresce a renda é a oferta de alimentos com a Certificação Orgânica Participativa pela Rede Ecovida com o uso do Selo Brasil Orgânico. Embora a legislação de orgânicos seja nacional, neste local as agroindústrias não possuíam a certificação, a qual é feita pela Rede Ecovida de Agroecologia, constituindo uma novidade importante a comercialização gerada pelos grupos de agricultores ecologistas. Pode-se conceituá-la como uma novidade organizacional e mercadológica encontrada pelos agricultores para acessar os mercados institucionais (licitações e programas governamentais) e para atrair novos consumidores a fim de assegurar a renda das famílias. Geralmente, os preços dos alimentos orgânicos se sobrepõem aos demais. De acordo com a pesquisa de campo, as variações de preço ocorrem conforme o caso e o tipo de alimento, mas transitam em média entre $20 \%$ e $200 \%$ em comparação com alimentos que não são orgânicos, sendo chamado de preço premium pela literatura de comercialização de alimentos ecológicos (ZAMBERLAN; BÜTTENBENDER; SPAREMBERGER, 2006).

\footnotetext{
7 Embora nos últimos anos (2014 em diante) os preços deixaram de ser reajustados pelo Estado, devido à crise econômica e institucional, assim, alguns preços deixaram se ser 'superiores' ou compensadores para os alimentos vendidos para estes canais.
} 


\section{CONSIDERAÇÕES FINAIS}

O objetivo do trabalho foi identificar e analisar as motivações e os diferentes tipos de novidades nos sistemas produtivos e nas agroindústrias familiares e seus efeitos nas famílias e nos processos de desenvolvimento rural e regional. Por meio do processo de investigação foi possível perceber a importância da capacidade de agência dos atores sociais para o desenvolvimento das novidades. Foram identificadas as motivações dos agricultores para construírem suas agroindústrias e analisadas novidades significativas aos processos de desenvolvimento rural e regional.

As principais motivações para a criação das agroindústrias foram o aumento de autonomia da família, acesso a novos conhecimentos, satisfação em produzir alimentos saudáveis e permanecer no campo. Além disso, pesaram na decisão das famílias a possibilidade de produção de alimentos ecológicos e construção de práticas mais sustentáveis. $\mathrm{O}$ aspecto que mais chama a atenção, contudo, é sua renda agroindustrial, que quase triplicou depois da instalação das agroindústrias, melhorando a qualidade de vida das famílias.

As novidades encontradas e analisadas no trabalho foram definidas como multidimensionais, pois podem ser agrupadas em cinco direções: produtivas, tecnológicas, organizacionais, ambientais e mercadológicas. As novidades, contudo, não estão fechadas apenas a uma classificação irrestrita; algumas possuem características de dois ou mais tipos de novidades, evidenciando características e resultados entrelaçados. Assim, como as mesmas não estão apenas dentro das agroindústrias familiares, mas em todo o processo de produção de matéria prima e nas relações sociais que os atores estabeleceram com outros atores, grupos, cooperativas e mercados, como no caso da rede social e territorial de apoio às agroindústrias.

Como resultados aos processos de desenvolvimento rural e regional destas novidades, pode-se afirmar que as mesmas geraram alterações em nível de nicho sociotécnico. Tais modificações proporcionaram melhores condições de vida e trabalho aos agricultores familiares, que puderam optar por permanecer no campo e produzir alimentos mais saudáveis, a partir de uma produção sustentável. As famílias estudadas passaram a comprar mais bens de consumo, viajar, participar de encontros, acessar Internet e investir em moradia, poupança, educação para os filhos e cursos de formação.

Além disso, as unidades produtivas passaram a consumir mais alimentos de produção própria. As ações coletivas alcançaram um público ainda maior, que vai além dos agricultores, abrange atores de desenvolvimento e grupos de consumidores. Estes últimos passam a adquirir alimentos mais sustentáveis e alteram suas dietas para formatos mais saudáveis. Em âmbito municipal, a renda dos agricultores garantiu uma movimentação do comércio local, além dos alimentos abastecerem escolas e creches de forma mais saudável e sustentável.

Durante a investigação foram identificadas três dificuldades enfrentadas pelas agroindústrias familiares, que podem, futuramente, comprometer as novidades geradas no nicho sociotécnico: (a) A sucessão familiar incerta, que põe em risco as novidades das agroindústrias e das cooperativas estudadas; (b) A dependência de algumas políticas públicas, como os mercados institucionais para a comercialização das cooperativas; (c) A instabilidade organizacional da rede de atores, que depende fortemente de um grupo específico de agricultores, da prefeitura e dos 
programas governamentais (PAA e Pnae), que se extintos ou reduzidos podem desestruturar a rede social e territorial que foi construída em torno dessas famílias e agroindústrias.

\section{REFERÊNCIAS}

BAGGIO, A. C. A sociedade de risco e a confiança nas relações de consumo. Revista de Direito Econômico e Socioambiental, Curitiba, PR, v. 1, n. 1, p. 127-147, 2010.

BULHÕES, F. M. Conhecimento e inovação no manejo de sistemas agroflorestais por citricultores ecológicos no Vale do Caí, RS. 2011. 308 f. Tese (Doutorado em Desenvolvimento Rural) - Universidade Federal do Rio Grande do Sul-UFRGS, Porto Alegre, 2011.

GAZOLLA, M.; SCHNEIDER, S. Conhecimentos, produção de novidades e transições sociotécnicas nas agroindústrias familiares. Organizações Rurais \& Agroindustriais, Lavras, v. 17, n. 2, p. 179-194, 2015.

GAZOLLA, M.; SCHNEIDER, S. (org.). Cadeias curtas e redes agroalimentares alternativas: negócios e mercados da agricultura familiar. Porto Alegre: Editora da UFRGS, 2017. 523 p. (Série Estudos Rurais).

GAZOLLA, M. Perspectiva multinível e coevolucionária e a noção de novidades no Desenvolvimento Rural e Regional: aplicações aos estudos das práticas criativas da Agricultura Familiar. Redes, Santa Cruz do Sul (on-line), v. 25, n. 1, p. 232-254, jan./abr. 2020.

GEELS, F. W.; SCHOT, J. Technological transitions as evolutionary reconfiguration processes: a multi-level perspectives and a case-study. Research Policy, n. 31, p. 1.257-1.274, 2002.

IBGE. Instituto Brasileiro de Geografia e Estatística - Cidades. Censo 2010. 2016. Disponível em: http://cidades.ibge.gov.br/xtras/perfil.php?lang=\&codmun=412860\&search=| | infogr\%E1ficos:-informa\%E7\%F5es-completas.

LONG, N. Sociología del desarrollo: una perspectiva centrada en el actor. México: Centro de Investigaciones y Estudios Superiores en Antropología Social, 2006. (Colección Investigaciones).

LONG, N.; PLOEG, J. D. Van Der. Heterogeneidade, ator e estrutura: para a reconstituição do conceito de estrutura. In: SCHNEIDER, S.; GAZOLLA, M. (org.). Os atores do desenvolvimento rural: perspectivas teóricas e práticas sociais. Porto Alegre: UFRGS, 2015. p. 21-48.

LOVATEL, M. Novidades e transições sociotécnicas em torno do leite orgânico: um estudo na Região Extremo Oeste de Santa Catarina. 2018. 195 f. Dissertação (Mestrado em Desenvolvimento Regional) - Universidade Tecnológica Federal do Paraná - UTFPR, 2018.

MARQUES, F. C. Velhos conhecimentos, novos desenvolvimentos: transições no regime sociotécnico da agricultura: a produção de novidades entre agricultores produtores de plantas medicinais no Sul do Brasil. 2009. 220 f. Tese (Doutorado em Desenvolvimento Rural) - Universidade Federal do Rio Grande do Sul - UFRGS, Porto Alegre, 2009.

MELLO, M. A. Sementes que brotam da crise: a produção de novidades organizacionais na agricultura familiar do Oeste de Santa Catarina. 2009. 299 f. Tese (Doutorado em Desenvolvimento Rural) - Universidade Federal do Rio Grande do Sul -UFRGS, Porto Alegre, 2009.

MINAYO, M. C. S. (org.). Pesquisa social: teoria, método e criatividade. 14. ed. Petrópolis, RJ: Vozes, 1999. MIOR, L. C. Agricultores familiares, agroindústrias e redes de desenvolvimento rural. Chapecó, SC: Editora Argos, 2005. 338 p.

MOORS, E. H. M.; RIP, A.; WISKERKE, J. S. C. The Dynamics of Innovation: A Multi-Level Co-Evolutionary Perspective. In: WISKERK, J. S. C.; PLOEG, J. D. Van Der. (org.). Seeds of Transition: essays on novelty production, niches and regimes in agriculture. Assen: Koninklijke Van Gorcum BV, 2004. p. 31-56.

MUTTI, R. O primado do outro sobre o mesmo... In: SEMINÁRIO DE ESTUDOS EM ANÁLISE DE DISCURSO, 1., 2003, Porto Alegre. Anais [...]. Porto Alegre, RS: UFRGS, nov. 2003. p. 10-13. [CD-ROM].

NIEDERLE, P. A. Indicações geográficas e processos de qualificação nos mercados agroalimentares. In: NIEDERLE, P. A. Indicações geográficas: qualidade e origem nos mercados alimentares. Porto Alegre: UFRGS. 2013. 296 p., p. 23-54 p. (Série Estudos Rurais).

OLIVEIRA, D. Produção de conhecimentos e inovações na transição agroecológica: o caso da agricultura ecológica de Ipê e Antônio Prado/RS. 2014. 232 p. Tese (Doutorado em Desenvolvimento Rural) - Universidade Federal do Rio Grande do Sul - UFRGS, 2014.

PLOEG, J. D. Van Der. Camponeses e impérios alimentares: lutas por autonomia e sustentabilidade na era da globalização. Porto Alegre: UFRGS, 2008. 
PLOEG, J. D. Van Der; BOUMA, J.; RIP, A.; RIJKENBERG, F. H. J.; VENTURA, F.; WISKERKE, J. S. C. On Regimes, Novelties, Niches and Co-Production. In: WISKERK, J. S. C.; PLOEG, J. D. Van Der. (org). Seeds of Transition: essays on novelty production, niches and regimes in agriculture. Assen: Koninklijke Van Gorcum BV, 2004. p. 1-29.

ROEP, Dirk; WISKERKE, Jhohannes S. C. 13 Reflecting on Novelty Production and Niches Management in Agriculture. In: PLOEG, J. D. Van Der; WISKERKE, J. S. C. (ed.). Seeds of transition: essays on novelty production, niches and regimes in agriculture. Wageningen: Royal Van Gorcum, 2004. 356 p.

STUIVER, M.; LEEUWIS, C.; PLOEG, J. D. van der. The power of experience: farmer's knowledge and sustainable innovations. In: WISKERKE, J. S. C.; PLOEG, J. D. Van Der. Seeds of Transition. Assen: Van Gorcun, 2004. p. 93-118.

WISKERKE, Han; PLOEG, Jan Douwe van der (eds.). Seeds of transition: essays on novelty production, niches and regimes in agriculture. Assen: Van Gorcum, 2004.

ZAMBERLAN, L.; BÜTTENBENDER, P. L.; SPAREMBERGER, A. O comportamento dos consumidores de produtos orgânicos e seus impactos nas estratégias de marketing. ENCONTRO ANPAD, 30., 2006. Salvador, BA, 2006. 